\title{
Chasing High Efficiency DSSC by Nano-Structural Surface Engineering at Low Processing Temperature for Titanium Dioxide Electrodes
}

\author{
Ying-Hung Chen, Chen-Hon Chen, Shu-Yuan $\mathrm{Wu}$, Chiung-Hsun Chen, \\ Ming-Yi Hsu, Keh-Chang Chen and Ju-Liang He \\ Department of Materials Science and Engineering, Feng Chia University \\ Taichung, Taiwan, \\ R.O.C.
}

\section{Introduction}

The rapid shortage of petrochemical energy has led to the great demand in developing clean and renewable energy sources; such as solar cells in these years. The first commercially available photovoltaic cell (PV) by using solar energy is silicon-based solar cell however with high production cost and high energy payback time. This limited the usage and agitated vigorous studies on the next-generation solar cells in order to reduce cost and increase efficiency. It was until 1991, dye-sensitized solar cells (DSSCs) have attracted increasing interests by the pioneering work of O'Regan and Grätzel. They used a Ru-based dye to achieve higher conversion efficiency in a cell made of titania $\left(\mathrm{TiO}_{2}\right)$ as the active layer. Recent development of solar cells in dye-sensitized type devices is one great step forward in the field. The DSSCs take advantages in simple fabrication technique and low production costs in contrast to those conventional silicon-based solar cells.

The DSSC device (Fig. 1) is basically comprised of two facing electrodes: a transparent photoanode, consisting of a mesoporous large band gap semiconductor as an active layer, modified with a monolayer of dye molecules and a Pt counter electrode, both deposited on conductive glass substrates, for example: indium tin oxide (ITO) glass. An appropriate medium containing the redox couple (usually $\mathrm{I}^{-} / \mathrm{I}_{3}-$ ) is placed between the two electrodes to transfer the charges. Among other semiconductors employed as the active layer of the DSSCs, titania known to have wide energy band gap, can absorb dye and is capable of generating electron-hole pairs via photovoltaic effect. DSSCs based on mesoporous titania, which exhibits very high specific surface area (and better dye-absorbing) has been drawn much attention over the past few years. A number of surface modification techniques have been reported to produce nanostructural $\mathrm{TiO}_{2}$ layer. Moreover, researchers suggested that one dimensional nanostructural $\mathrm{TiO}_{2}$ such as nano-rods, nano-wires or nano-tubes is an alternative approach for higher PV efficiency due to straightforward diffusion path of the free electron once being generated. For these reasons, we use several cost-effective manufacturing methods to develop the nanostructural $\mathrm{TiO}_{2}$ electrode at near room 
temperature to form several types of DSSC device configuration and to investigate their PV efficiency. The aim is to develop feasible routes for commercializing DSSCs with high PV efficiency.

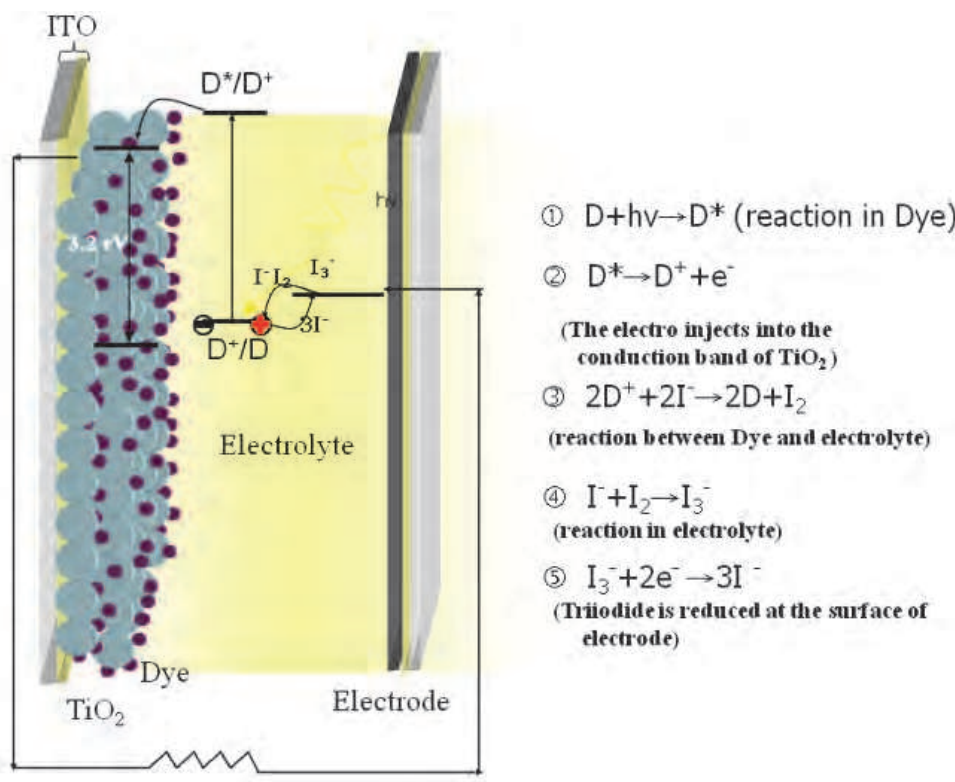

Fig. 1. Schematic of the principle for dye sensitized solar cell to indicate the electron energy level in different phases. (The electrode sensitizer, $\mathrm{D} ; \mathrm{D}^{*}$, electronically excited sensitizer; $\mathrm{D}^{+}$, oxidized sensitizer)

This chapter demonstrates four kinds of manufacturing methods to obtaion nanostructural photoanode for the purpose of achieving high efficiency DSSCs. These manufacturing methods were involved with each method chosen with good reason, but went out with different performance. These involves liquid phase deposition (LPD) to grow $\mathrm{TiO}_{2}$ nanoclusters layer, hydrothermal route (HR) to obtain $\mathrm{TiO}_{2}$ nanowires, $P V D$ titanium followed by anodic oxidation to grow $\mathrm{TiO}_{2}$ nanotubes, and eventually microarc oxidation (MAO) /alkali etching to produce nanoflaky $\mathrm{TiO}_{2}$. The first three methods can directly grow $\mathrm{TiO}_{2}$ layer on ITO glass and the specimens were assembled into ITO glass/[TiO $2(\mathrm{~N} 3$ dye $)] / \mathrm{I}_{2}+\mathrm{LiI} / \mathrm{Pt} / \mathrm{ITO}$ glass device. The last method can only obtain $\mathrm{TiO}_{2}$ layer on titanium and was assembled into $\mathrm{Ti} /\left[\mathrm{TiO}_{2}(\mathrm{~N} 3\right.$ dye) $] / \mathrm{I}_{2}+\mathrm{LiI} / \mathrm{Pt} / \mathrm{ITO}$ glass inverted-type device. Microstructural characterization and observation work for the obtained nano featured $\mathrm{TiO}_{2}$ were carried out using different material analyzing techniques such as field-emission scanning electron microscopy, high-resolution transmission electron microscopy and X-ray diffractometry. All the PV measurements were based on a large effective area of $1 \mathrm{~cm} \times 1 \mathrm{~cm}$. The DSSC sample devices were then irradiated by using a xenon lamp with a light intensity of $6 \mathrm{~mW} / \mathrm{cm}^{2}$, which apparently is far lower than the standard solar simulator $\left(100 \mathrm{~mW} / \mathrm{cm}^{2}\right)$. It would then be true for the photovoltaic data reported in this article for cross-reference within this article and not validated for inter-laboratory cross-reference. Photocurrent-voltage $(I-V)$ characteristics were obtained using a potentiostat (EG\&G 263A). Photovoltaic efficiency of 
each cell was calculated from $I-V$ curves. The results for each study are reported and discussed with respect to their microstructure as below.

\section{Nanocluster- $\mathrm{TiO}_{2}$ layer prepared by liquid phase deposition}

The LPD process, which was developed in recent years, is a designed wet chemical film process firstly by Nagayama in 1988. Than Herbig et al. used LPD to prepare $\mathrm{TiO}_{2}$ thin film and studied its photocatalytic activity. Most vacuum-based technologies such as sputtering and evaporation are basically limited to the line-of-sight deposition of materials and cannot easily be applied to rather complex geometries. By contract, the easy production, no vacuum requirement, self-assembled and compliance to complicated geometry substrate has led many LPD applications for functional thin films. In order to directly grow nanocluster- $\mathrm{TiO}_{2}$ on ITO glass, the simplest method - LPD process was firstly considered by using $\mathrm{H}_{2} \mathrm{TiF}_{6}$ and $\mathrm{H}_{3} \mathrm{BO}_{3}$ as precursors. The reaction steps involved to obtain nanocluster- $\mathrm{TiO}_{2}$ are illustrated as followed. The $\mathrm{H}_{3} \mathrm{BO}_{3}$ pushes eq. (1) to form eventually $\mathrm{Ti}(\mathrm{OH})_{6}{ }^{2-}$ which transforms into $\mathrm{TiO}_{2}$ after thermal annealing.

$$
\begin{gathered}
\left(\mathrm{TiF}_{6}\right)^{2-}+n \mathrm{H}_{2} \mathrm{O} \leftrightarrow \mathrm{TiF}_{6-n}(\mathrm{OH})_{n}^{2-}+n \mathrm{HF} \\
\mathrm{H}_{3} \mathrm{BO}_{3}+4 \mathrm{HF} \leftrightarrow B F^{4+}+\mathrm{H}_{3} \mathrm{O}+2 \mathrm{H}_{2} \mathrm{O}
\end{gathered}
$$

Here, the influence of deposition variables including deposition time and post-heat treatment on the microstructure of $\mathrm{TiO}_{2}$ layer and the photovoltaic property was studied. The LPD system to deposit titania film is schematically shown in Fig. 2.

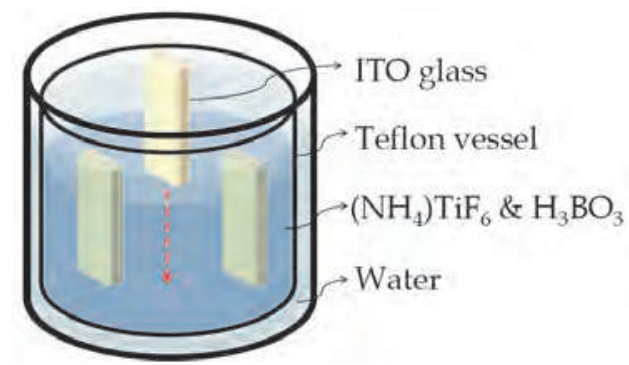

Fig. 2. Schematic diagram of $\mathrm{LPD}^{-\mathrm{TiO}_{2}}$ deposition system.

Figure. 3 shows the $I-V$ characteristics of the DSSCs assembled by using $\mathrm{TiO}_{2}$ films deposited for different time, with their corresponding surface and cross sectional film morphology also shown. It was indeed capable of producing nanocluster featured $\mathrm{TiO}_{2}$ films shown in the surface morphology, regardless of the deposition time. It can also be found that the $I-V$ characteristics are sensitive to the $\mathrm{TiO}_{2}$ film deposition time, but unfortunately non-linearly responded to the deposition time. By careful examination on the surface morphology of these $\mathrm{TiO}_{2}$ films deposited at different deposition time, the film obtained at longer period of deposition time, say $60 \mathrm{~h}$ presents no longer nanocluster feature, but cracked-chips feature instead. This significantly reduces the open circuit voltage $\left(V_{o c}\right)$ as well as the short circuit current density $\left(J_{s c}\right)$. It shall be a consequence of the cracks that leads to the direct electrolyte contact to the front window layer (to reduce $V_{o c}$ ) and the 
reduced specific surface area (to reduce $J_{s c}$ ). Further exam cross sectional morphology of the $\mathrm{TiO}_{2}$ films as a function of deposition time, it was found that the film thickness does not linearly respond to the deposition time. This shall be the gradual loss of reactivity of the electrolyte liquid. Therefore, it is not practical to increase the film thickness by an extended deposition time. Still, we believed that by constant precursor supplement into the electrolyte liquid, it would refresh the liquid and certainly the increased film growth rate, of course with the price of process monitoring automation.

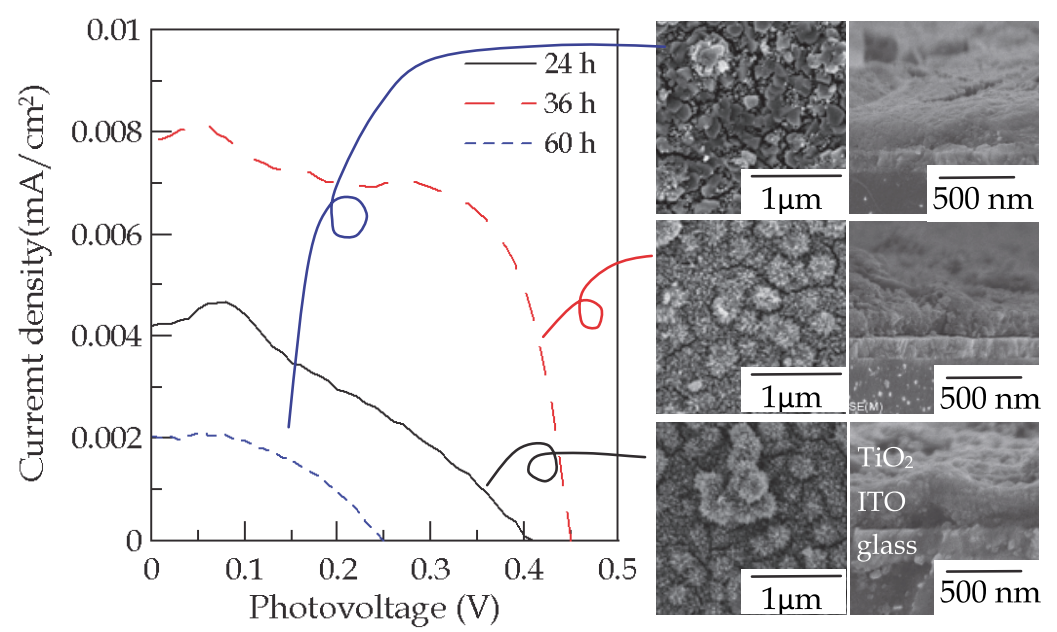

Fig. 3. I- $V$ characteristic of the cell assembled by $\mathrm{LPD}^{-\mathrm{TiO}_{2}}$ under different deposition time, with their corresponding surface and cross sectional film morphology.

Fig. 4 shows the XRD patterns of the $\mathrm{TiO}_{2}$ film with different annealing temperature. The results indicate that the as-deposited film was amorphous due to the low LPD growth temperature. Annealing provides thermal energy as a driving force to overcome activation energy that required for crystal nucleation and growth. The exact $\mathrm{TiO}_{2}$ phase to be effective for DSSC has been known to be anatase, which can found that the peak ascribed to anatase phase $\mathrm{A}(101)$ can only appear over $400{ }^{\circ} \mathrm{C}$ and become stronger over $600{ }^{\circ} \mathrm{C}$, ie. better crystallinity of the film annealed at higher temperature. Over an annealing temperature of $600{ }^{\circ} \mathrm{C}$ leads to the ITO glass distortion.

The $I-V$ characteristics of the DSSCs assembled by using $\mathrm{TiO}_{2}$ films with different annealing temperatures, with their corresponding surface and cross sectional film morphology are shown in Fig. 5. The $\mathrm{TiO}_{2}$ film surface forms numerous tiny nanocracks and needle-like structures with increasing annealing temperature. It can be found that the $I-V$ characteristics are sensitive to the $\mathrm{TiO}_{2}$ film annealing temperatures and the $J_{s c}$ increases straight up to a maximum when annealed at $600{ }^{\circ} \mathrm{C}$. Apparently, the increase of $J_{s c}$ shall be associated with the reformation of the $\mathrm{TiO}_{2}$ film morphology and the increased film crystallinity. By reforming numerous tiny nanocracks and needle-like structures, the $\mathrm{TiO}_{2}$ film has more specific surface area after post-annealing and achieves higher efficiency dye adsorbing. However, the negative effect of annealing occurred to the significant increase of the ITO electrical resistance that causes the $V_{o c}$ drop off as can be seen in Fig. 5. Anyhow, the overall increased photovoltaic efficiency as a function of annealing temperature is an encouraging 
result of this study using PLD to obtain $\mathrm{TiO}_{2}$ film and post-annealing for DSSC photoanode preparation.

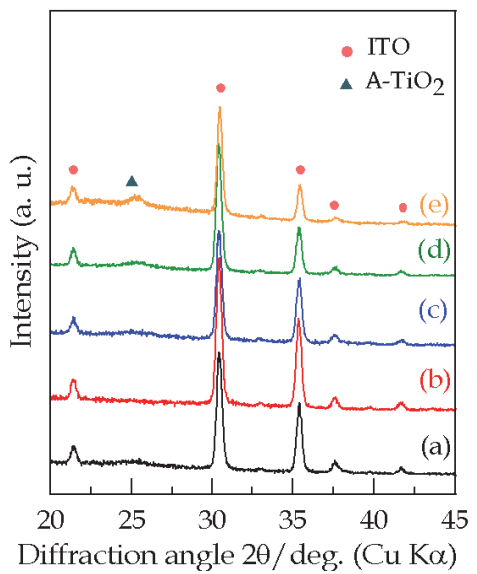

Fig. 4. XRD patterns of (a) ITO glass substrate, (b) $\mathrm{TiO}_{2}$ as-deposited specimen, and the post annealed specimens obtained at (c) 200, (d) 400 and (e) $600{ }^{\circ} \mathrm{C}$ for $30 \mathrm{~min}$.

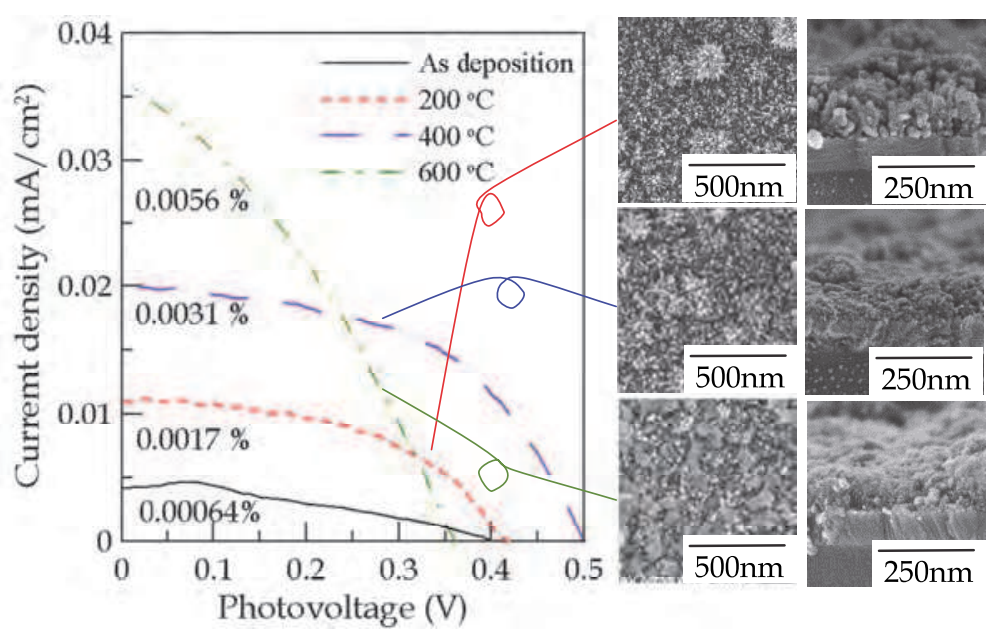

Fig. 5. I- $V$ characteristic of the cell assembled by $\mathrm{LPD}-\mathrm{TiO}_{2}$ under different annealing temperature, with their corresponding surface and cross sectional film morphology.

\subsection{Summary}

In this paragraph, a LPD system is used to prepare the $\mathrm{TiO}_{2}$ layer on ITO glass at the room temperature followed by post-annealing as the photoanode in DSSC. The result is closely connected to the variation of microstructure including both the specific surface area and crystal structure. This demonstration work confirms the truth that the LPD method is capable of obtaining nanocluster $\mathrm{TiO}_{2}$ and with crystallinic anatase structure through 
suitable annealing treatment. Unfortunately, the unacceptable $\mathrm{LPD}^{-\mathrm{TiO}_{2}}$ film growth has led some other attempts to obtain nano-structural $\mathrm{TiO}_{2}$ layer. These methods are sketched as below.

\section{3. $\mathrm{TiO}_{2}$ nanowires growth on $\mathrm{TiO}_{2}$ template via hydrothermal route}

As being well acknowledged that pressurized hydrothermal route is able to synthesize 1D nanomaterials without using catalysts. Due to 1D nanomaterials (such as nanowires) having a relatively higher interfacial charge transfer rate and specific surface area compared with the spherical $\mathrm{TiO}_{2}$ particles and nanocluster $\mathrm{TiO}_{2}$, the simple operation, fast formation and low cost process interested us using this method to produce $\mathrm{TiO}_{2}$ nanowires. The idea was that via the hydrothermal (HR) growth of $\mathrm{TiO}_{2}$ nanowires on an arc ion plated (AIP) $\mathrm{TiO}_{2}$ layer (as a template during HR and a barrier layer during service that pre-deposited on ITO glass), the obtained film would be able to exhibit the desired photoanode properties. AIP is known to be capable of producing high growth rate, high density and strong adhesion films without additional substrate heating, the pre-deposited $\mathrm{AIP}-\mathrm{TiO}_{2}$ template might also be able to get rid of the autoclave while at least well-aligned or randomly-oriented $\mathrm{TiO}_{2}$ nanowire can be grown. In this study, anatase Degussa TG-P25 powder was used as starting material. Eventually, the experimental result showed the randomly-orientated $\mathrm{TiO}_{2}$ nanowires were formed on $\mathrm{AIP}-\mathrm{TiO}_{2}$ template. $\mathrm{TiO}_{2}$ powder content in the HR bath $(\mathrm{g} / \mathrm{l})$ and post-annealing temperature were evaluated their microstructure and photovoltaic efficiency of the assembled DSSC devices. The HR system and preparation method to obtain $\mathrm{TiO}_{2}$ nanowires is illustrated in Fig. 6.

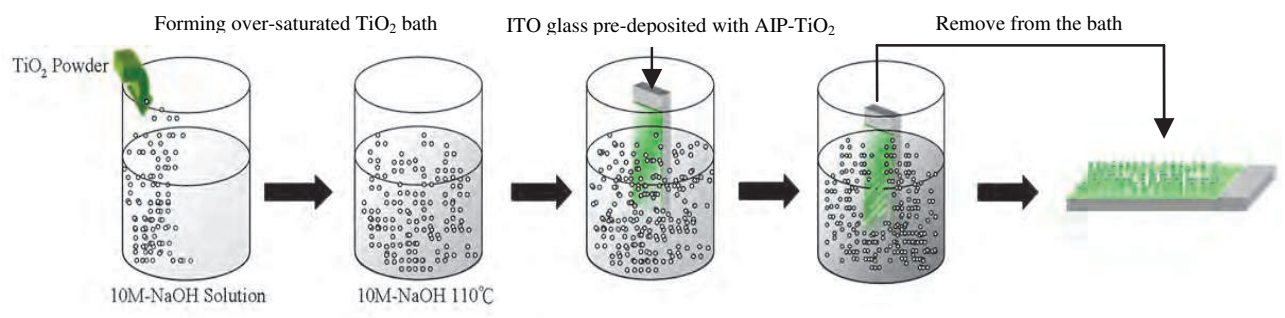

Fig. 6. The HR system and preparation method to obtain $\mathrm{TiO}_{2}$ nanowires.

Figure. 7 shows the $I-V$ characteristics of the DSSCs assembled by using $\mathrm{HR}-\mathrm{TiO}_{2}$ as the photoanode deposited at different $\mathrm{TiO}_{2}$ powder content, with their corresponding surface and cross sectional film morphology also shown. The dense columnar $\mathrm{AIP}-\mathrm{TiO}_{2}$ bottom layer can partially be seen in cross sectional view for each specimen. The result of $I-V$ curve for the DSSC assembled directly from Degussa TG-P25 as the photoanode is also shown. The HR was indeed capable of generating randomly-stacked $\mathrm{TiO}_{2}$ nanowires on template, regardless of the $\mathrm{TiO}_{2}$ content. It can also be found that the $I-V$ characteristics are sensitive to the $\mathrm{TiO}_{2}$ powder content, but unfortunately non-linearly responded. The $\mathrm{HR}-\mathrm{TiO}_{2}$ obtained at high $\mathrm{TiO}_{2}$ content, say $75 \mathrm{~g} / 1$, presents no longer nanowires, but agglomerated powdery feature instead. This corresponds to a less specific surface area for dye adsorption and a decreased overall photovoltaic efficiency (mainly cause a reduction of the $J_{s c}$ ). From cross sectional image, the as-grown $\mathrm{HR}-\mathrm{TiO}_{2}$ thickness is insusceptible to the $\mathrm{TiO}_{2}$ powder 
content. Ultimately, the highest photovoltaic efficiency of $3.63 \%$ is achieved for the $\mathrm{HR}-\mathrm{TiO}_{2}$ obtained at a $50 \mathrm{~g} / 1 \mathrm{TiO}_{2}$ powder content. Interestingly, some of the photovoltaic efficiency of DSSCs assembled from $\mathrm{HR}-\mathrm{TiO}_{2}$ nanowires surpassing that of the DSSC assembled from Degussa P-25 powder, proves that using the one-dimensional structure to enhance DSSC efficiency is conceptually correct.

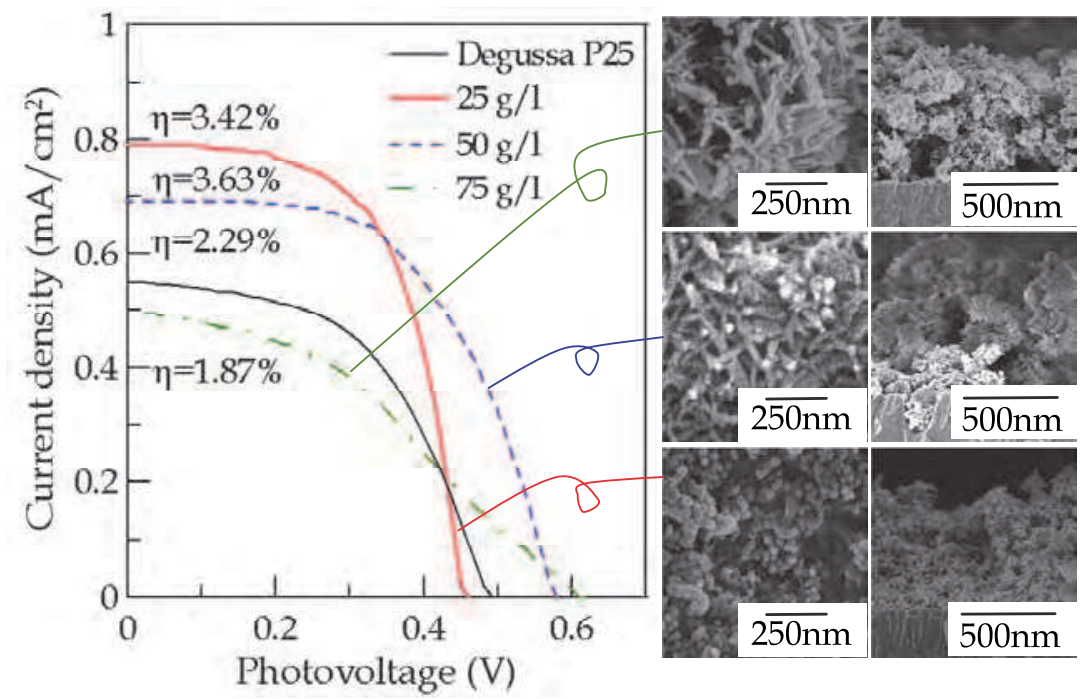

Fig. 7. $I-V$ characteristic of the DSSCs assembled by $\mathrm{HR}^{-\mathrm{TiO}_{2}}$ as photoanode prepared under different amount of $\mathrm{TiO}_{2}$ powder, with their corresponding surface and cross sectional film morphology.

The $I-V$ characteristics of the DSSCs assembled with $\mathrm{HR}-\mathrm{TiO}_{2}$ nanowires on template and annealed at different temperatures, with their corresponding XRD pattern and surface morphology are also shown in Fig. 8. Basically, the as-grown $\mathrm{HR}-\mathrm{TiO}_{2}$ nanowires are amorphous and account for the lowest $J_{s c}$ of the assembled DSSCs. However, the high crystallinity of the AIP- $\mathrm{TiO}_{2}$ bottom layer facilitates the diffraction peaks shown in the XRD patterns, even though amorphous $\mathrm{HR}-\mathrm{TiO}_{2}$ nanowires cover all over the top. By knowing this, the specimens with the $\mathrm{HR}-\mathrm{TiO}_{2}$ nanowires on template shown in XRD patterns give a gradual increase in peak intensity when annealing temperature is increased. Apparently, this shall be due to the improved crystallinity of the $\mathrm{HR}-\mathrm{TiO}_{2}$ nanowires by the annealing process. This helps for the increased $J_{s c}$ of the assembled DSSCs as can be observed in Fig. 8 . The annealing crystallized $\mathrm{HR}-\mathrm{TiO}_{2}$ nanowires provides more surface area for dye absorbing and thus the increased $J_{s c}$ of the assembled DSSCs. The side effect accompanied with annealing to the $\mathrm{TiO}_{2}$ nanowires is the decrease in $V_{o c}$ of the assembled DSSCs as can be seen again in Fig. 8. This can be ascribed to the volume change of the re-grown $\mathrm{HR}-\mathrm{TiO}_{2}$ that pays for the open channel for the $\mathrm{I}_{2}+\mathrm{LiI}$ liquid electrolyte to be in direct contact with the AIP-TiO bottom layer. The ultimate PV efficiency of $3.63 \%$ can be achieved in this study. By using this method, annealing temperature shall however be carefully selected to trade-off the $J_{s c}$ and $V_{o c}$ of the assembled DSSCs. 


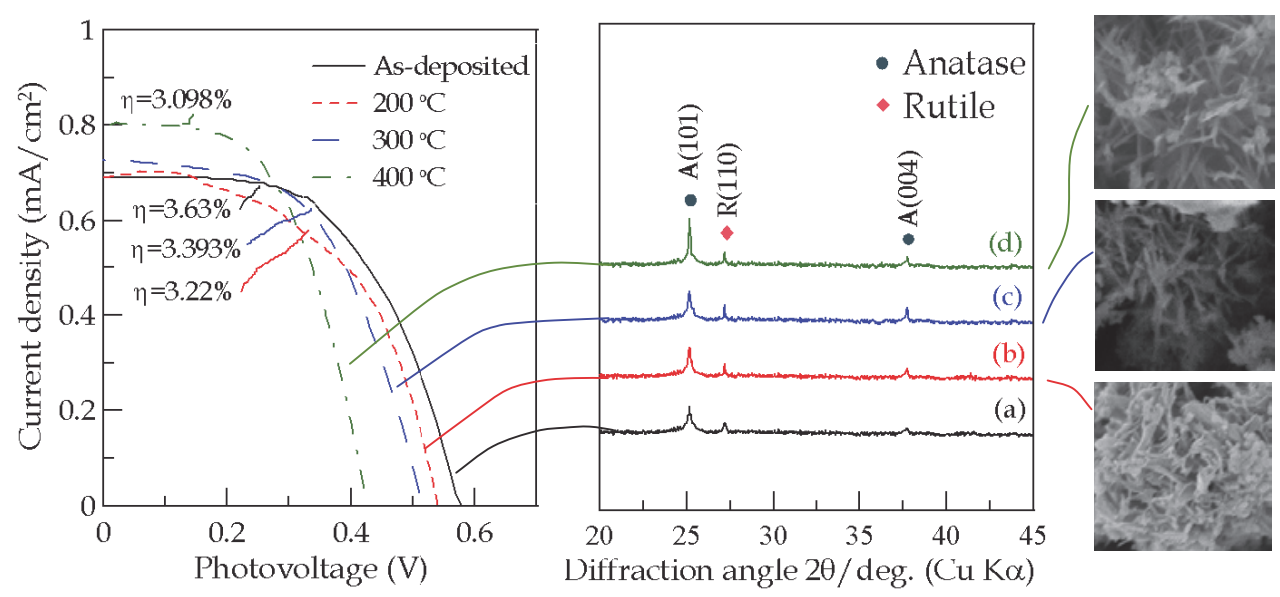

Fig. 8. (a) $I-V$ characteristics of the DSSCs assembled with $\mathrm{HR}$ grown $\mathrm{TiO}_{2}$ nanowires on template and annealed at (b) 200, (c) 300 and (d) $400{ }^{\circ} \mathrm{C}$ for $30 \mathrm{~min}$, with their corresponding XRD pattern and surface morphology

\subsection{Summary}

In this study, hydrothermal method was demostrated to successfully prepare the randomlyorientated $\mathrm{TiO}_{2}$ nanowires on AIP-TiO ${ }_{2}$ template. A cell of ITO glass/AIP-TiO $/[$ nanowire$\mathrm{TiO}_{2}$ (N3 dye)]/ $\mathrm{I}_{2}+\mathrm{LiI}$ electrolyte/Pt/ITO glass was constructed. Although $\mathrm{TiO}_{2}$ nanowires randomly-orientated, it possesses remarkable PV efficiency. By optimizing hydrothermal process condition and annealing treatment, an ultimate PV efficiency of $3.63 \%$ can be achieved. The $\mathrm{AIP}-\mathrm{TiO}_{2}$ accidentally acts as a block layer for the $\mathrm{I}_{2}+\mathrm{LiI}$ electrolyte in the assembled PV device. A hydrothermal treatment time so long as 24 hours shall be required for achieving this, which however has shorter treatment time than the LPD process and a fair PV efficiency without post-thermal annealing. This study also implicates a new possibility for 1-D nanomaterial, such as nanotubes, that can rapidly transfer of the charge carriers along the length of $\mathrm{TiO}_{2}$ nanotubes. The method to grow the $\mathrm{TiO}_{2}$ nanotubes is sketched as below.

\section{PVD titanium followed by anodic oxidation to grow $\mathrm{TiO}_{2}$ nanotubes}

Anodization is one promising route to prepare long and highly ordered $\mathrm{TiO}_{2}$ nanotubes array. This has been demonstrated by Shankar et al. who synthesized $\mathrm{TiO}_{2}$ nanotube array on titanium foil with a tube length up to $220 \mu \mathrm{m}$. Very short anodic oxidation treatment time is required as compared to LPD and HR and might bring this technique a step further toward industrial practice. However, this tube-on-foil design may potentially only be applied as a back-side illuminated DSSCs which are predestined to deplete certain quantity of incident light while traveling through the $\mathrm{I}_{2}+\mathrm{LiI}$ electrolyte. Direct growth of $\mathrm{TiO}_{2}$ nanotubes array on transparent conducting oxide (TCO) glass substrate via anodizing a sputtering-deposited or evaporation-deposited titanium layer on TCO for constructing front-side illuminated DSSCs has been attempted, but suffering with a problem of easy detachment of the $\mathrm{TiO}_{2}$ nanotubes array. By considering this, a two-step method involving 
AIP metal titanium film on ITO glass followed by anodic oxidation was proposed. A tenaciously and dense AIP titanium layer was obtained and was bearable for subsequent anodic oxidation. In this approach, $\mathrm{TiO}_{2}$ nanotubes array was successfully formed by anodizing the pre-deposited AIP metal Ti on ITO glass. A $5 \mu$ m-thick metal Ti layer can be used to convert into a $10 \mu$ m-thick amorphous $\mathrm{TiO}_{2}$ nanotubes array by anodic oxidation for $2 \mathrm{~h} . \mathrm{NH}_{4} \mathrm{~F}$ and $\mathrm{H}_{2} \mathrm{O}$ addition in the ethylene glycol (EG) bath and post-heat treatment on the microstructure of $\mathrm{TiO}_{2}$ nanotube array in responding to the photovoltaic property of the assembled DSSCs were investigated.

For better morphological control of $\mathrm{TiO}_{2}$ nanotubes before further evaluation on the microstructure and photovoltaic property, the $\mathrm{TiO}_{2}$ nanotubes growth mechanism was revealed during anodic oxidation, anodic current occurring to the specimen was recorded and the accompanied surface morphology was observed through the whole stages as shown in Fig. 9. It is seen that a rapid decrease of current density is caused when a thin passivated oxide layer was developed on the Ti surface in the beginning stage as can be seen in Fig. 9(a). Then, localized dissolution of the oxide layer begins to form pits over the entire oxide layer surface. This causes a small turbulent current density as presented in Fig. 9(b). At the bottom of each pit, the relatively thinner oxide layer (than that around the periphery) facilitates a localized electric field intensity across the oxide layer and drives the pit growth inward further. The continuing growth of the pit pushes oxide/metal interface inward while charge exchange occurs to the inner wall of the pit to form nanotube. At the same time, a steady-state current density is observed as can be seen in Fig. 9(c). An extended anodizing time can completely consumes the pre-deposited titanium metal layer and rapid decrease in current density is observed as shown in Fig. 9(d).

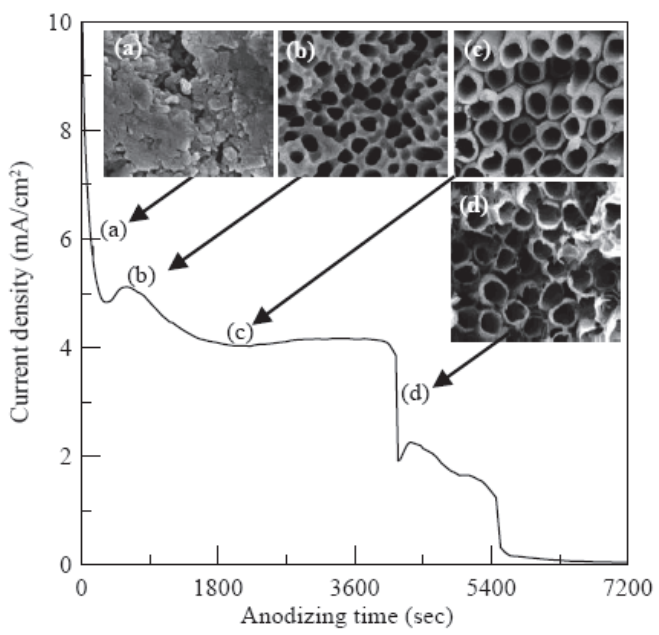

Fig. 9. Current density and surface morphology variation during anodic oxidation.

For exploring the effect of anodizing bath composition on the microstructural evolution of the grown $\mathrm{TiO}_{2}$ nanotubes, five different types of bath composition were evaluated and their composition were listed in Table 1, where bath $\mathrm{A}, \mathrm{B}$ and $\mathrm{C}$ are different in content of $\mathrm{H}_{2} \mathrm{O}$ addition and bath $\mathrm{B}, \mathrm{D}$ and $\mathrm{E}$ are different in content of $\mathrm{NH}_{4} \mathrm{~F}$ addition. Fig. 10 shows the SEM observation result of the $\mathrm{TiO}_{2}$ nanotubes arrays anodized in the bath $\mathrm{A}, \mathrm{B}, \mathrm{C}, \mathrm{D}$ and $\mathrm{E}$. 
It was indeed capable of producing nanotube featured $\mathrm{TiO}_{2}$ films shown in the SEM morphology, regardless of the electrolyte composition. It can be noted that the entire grown $\mathrm{TiO}_{2}$ nanotubes array (using whatever electrolyte bath) are strongly adhered on the ITO glass. Some $\mathrm{TiO}_{2}$ nanotubes grow slower at specific electrolyte composition (bath $\mathrm{D}$ and $\mathrm{E}$ for example) and leave a remnant titanium layer (identified separately as a-titanium) beneath the nanotubes.

\begin{tabular}{ll}
\hline Electrolyte bath & Composition \\
\hline A & $1 \mathrm{~L} \mathrm{EG}+3 \mathrm{~g} \mathrm{NH}_{4} \mathrm{~F}+0.1 \mathrm{~g} \mathrm{H}_{2} \mathrm{O}$ \\
$\mathrm{B}$ & $1 \mathrm{~L} \mathrm{EG}+3 \mathrm{~g} \mathrm{NH}_{4} \mathrm{~F}+20 \mathrm{~g} \mathrm{H}_{2} \mathrm{O}$ \\
$\mathrm{C}$ & $1 \mathrm{~L} \mathrm{EG}+3 \mathrm{~g} \mathrm{NH}_{4} \mathrm{~F}+40 \mathrm{~g} \mathrm{H}_{2} \mathrm{O}$ \\
$\mathrm{D}$ & $1 \mathrm{~L} \mathrm{EG}+1.5 \mathrm{~g} \mathrm{NH}_{4} \mathrm{~F}+20 \mathrm{~g} \mathrm{H}_{2} \mathrm{O}$ \\
$\mathrm{E}$ & $1 \mathrm{LEG}+2 \mathrm{~g} \mathrm{NH}_{4} \mathrm{~F}+20 \mathrm{~g} \mathrm{H}_{2} \mathrm{O}$ \\
\hline
\end{tabular}

Table 1. Electrolyte composition used in this study for anodization to obtain $\mathrm{TiO}_{2}$ nanotubes.

More quantitative comparison of the SEM observations, the tube length, inner diameter and outer diameter of the $\mathrm{TiO}_{2}$ nanotubes anodized in electrolytes $\mathrm{A}, \mathrm{B}, \mathrm{C}, \mathrm{D}$ and $\mathrm{E}$ are measured and drawn in Fig. 10. For electrolyte A, B and C (in sequence of increasing water content of the electrolyte), the tube length and tube diameter (inner and outer) are bar chart illustrated in Fig. 10 (upper right). The water content is found to not only influence the tube diameter but also the tube length. With increasing water content, the tube length decreases, but the tube diameters increase. One explanation for this is that the $\mathrm{H}_{2} \mathrm{O}$ not only inhibits nanotubes growth but also dilutes the reactivity of $\mathrm{NH}_{4} \mathrm{~F}$ of the electrolyte. On the other hand for electrolyte $\mathrm{D}, \mathrm{B}$ and $\mathrm{E}$ (in sequence of increasing $\mathrm{NH}_{4} \mathrm{~F}$ content of the electrolyte), the tube length and tube diameter (inner and outer) are also bar chart illustrated in Fig. 10 (bottom right). It can be found that increasing $\mathrm{NH}_{4} \mathrm{~F}$ content of the electrolyte prompts the tube growth rate to obtain longer tubes while at the same time with a decreased diameter. In this regard, $\mathrm{NH}_{4} \mathrm{~F}$ behaves as the active regent for the formation of nanotubes and restricts lateral growth of the nanotubes. As a whole of anodizing variables study here, it demonstrates a feasible way to convert AIP metal titanium layer into $\mathrm{TiO}_{2}$ nanotubes array on the ITO glass by anodic oxidization procedure. The firmly adhered AIP metal titanium layer guarantees the successful growth of $\mathrm{TiO}_{2}$ nanotubes. By knowing this and compromising tube length and diameters, the following $I-V$ characteristics study for the DSSCs assembled by using $\mathrm{TiO}_{2}$ nanowirs are based on the electrolyte $\mathrm{B}$.

The $I-V$ characteristics of the DSSCs assembled by using $\mathrm{TiO}_{2}$ nanowirss with different annealing temperatures, with their corresponding XRD pattern was also shown in Fig. 11. As opposed to those Ti layer obtained by using sputter deposition, the AIP-deposited Ti layer exhibits mainly crystallinic a-Ti phase and account for the strong film adhesion. The as-anodized $\mathrm{TiO}_{2}$-nanotube array presents an X-ray amorphous structure with trace amount of remnant a-Ti. The diffraction peaks corresponding to anatase phase $\mathrm{TiO}_{2}$ can be found to appear in the specimens annealed over $250{ }^{\circ} \mathrm{C}$ indicating that the crystallization occurs to the amorphous $\mathrm{TiO}_{2}$ nanotubes after post-annealing. The intensity increase of the diffraction peaks corresponding to the anatase phase $\mathrm{TiO}_{2}$ shows that crystallinity of the nanotubes increases with the annealing temperature. However, the disappearing of the diffraction peak corresponding to remnant a-Ti can only be observed for the specimen annealed at $450{ }^{\circ} \mathrm{C}$. This suggests that complete thermal oxidation of remnant a-Ti layer took place at a temperature over $450{ }^{\circ} \mathrm{C}$. Furthermore, it can also be found that the $I-V$ characteristics are 
sensitive to the annealing temperature, the $J_{s c}$ in particular (due to the enhanced crystallinity of nanotubes). The $V_{o c}$ unfortunately on the contrary decreases with increasing postannealing temperature because of the negative effect devastated by the increased sheet resistance of the ITO film (measured but not shown). An overview of the photovoltaic efficiency of the cell assembled from the as-anodized and post-annealed $\mathrm{TiO}_{2}$-nanotube array, when an annealing temperature is over $350{ }^{\circ} \mathrm{C}$, a maximum efficiency of $1.88 \%$ can be obtained and subsequent a decrease in $J_{s c}$ occurs leading to a decreased efficiency of $0.53 \%$. Apparently, this result from two opposite competitive factors, i.e. the sheet resistance of the ITO film and the profitable crystallinity of $\mathrm{TiO}_{2}$ nanotubes, which can be affected by the post-annealing. When increasing post-annealing temperature, the improved crystallinity of the anatase $\mathrm{TiO}_{2}$ nanotubes array facilitates a more ideal electron migration path from dye to ITO front electrode, therefore an increased $J_{s c}$, but the abrupt increase in sheet resistance of the ITO film (over $450^{\circ} \mathrm{C}$ ) seriously hinders electron current flowing through it.
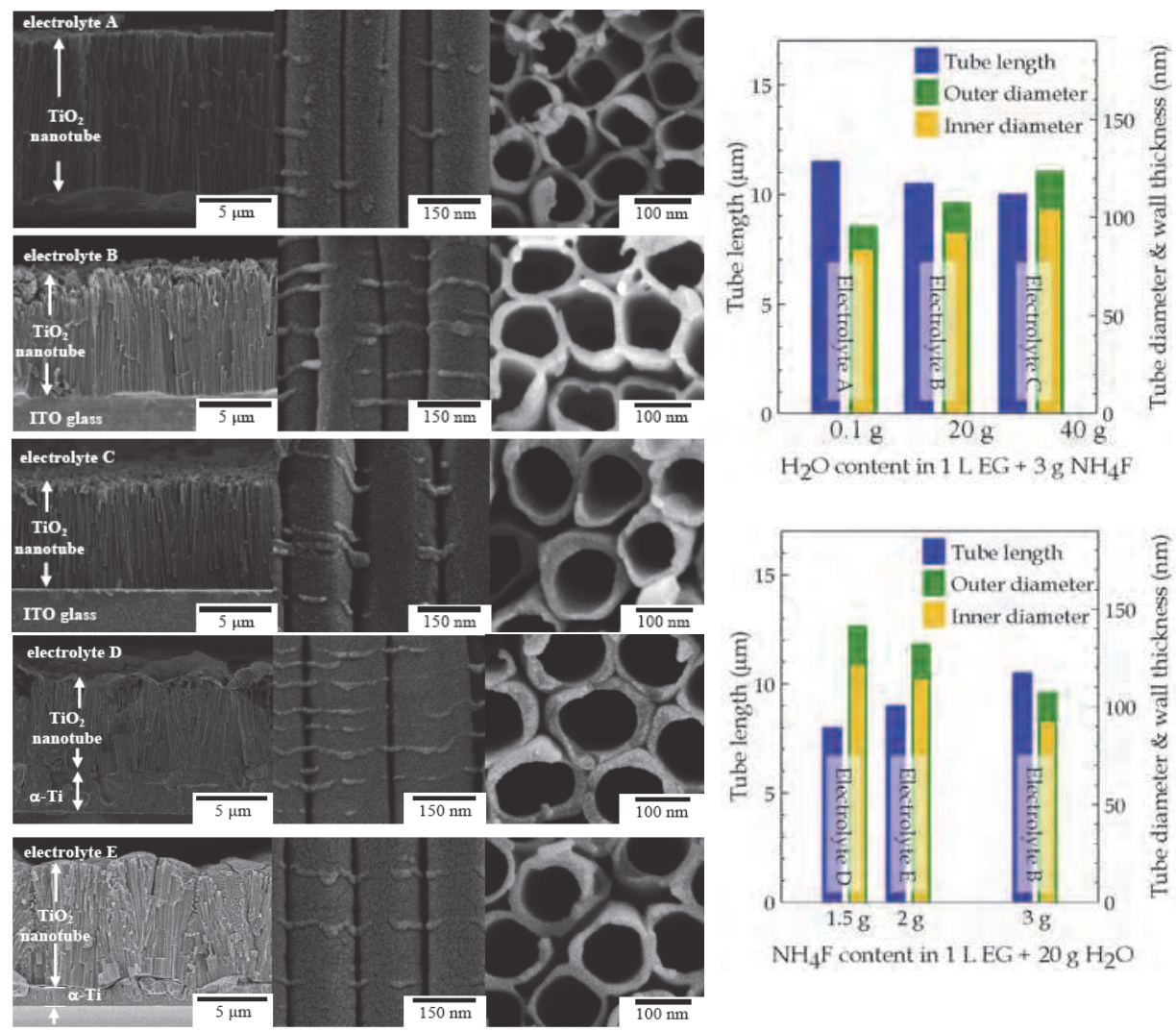

$\mathrm{H}_{2} \mathrm{O}$ content in $1 \mathrm{LEG}+3 \mathrm{~g} \mathrm{NH}_{4} \mathrm{~F}$

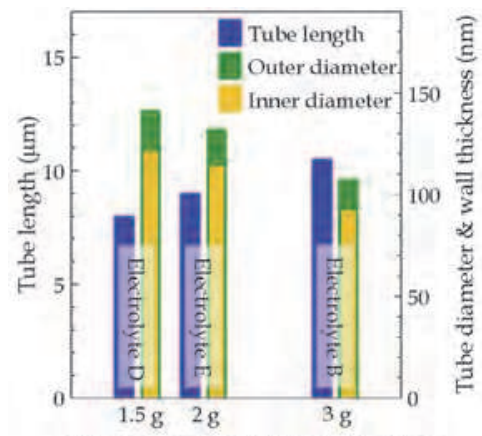

$\mathrm{NH}_{4} \mathrm{~F}$ content in $1 \mathrm{LEG}+20 \mathrm{~g} \mathrm{H}_{2} \mathrm{O}$

Fig. 10. SEM images of $\mathrm{TiO}_{2}$ nanotubes anodized in electrolyte bath $\mathrm{A}, \mathrm{B}, \mathrm{C}, \mathrm{D}$ and $\mathrm{E}$. The left pictures are through-thickness cross sectional view of the $\mathrm{TiO}_{2}$ nanotubes at low magnification, the middle pictures are magnified image of the tubes, the right pictures are top-view of the tubes. The tube length, inner diameter and outer diameter of the $\mathrm{TiO}_{2}$ nanotubes anodized in electrolytes A, B, C, D and E are also measured and compared. 


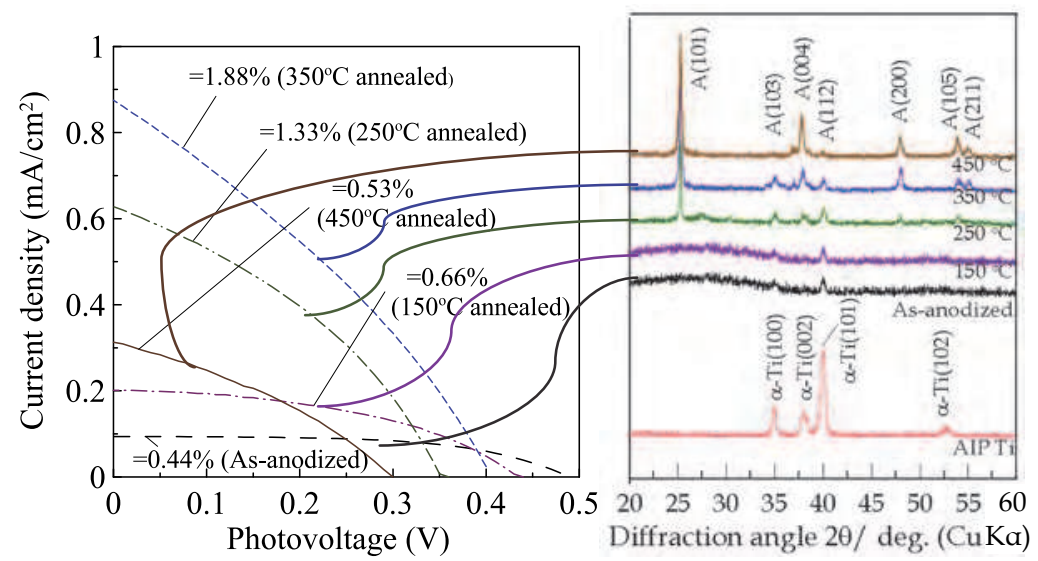

Fig. 11. $I-V$ characteristic of the cell assembled from the as-anodized and post-annealed $\mathrm{TiO}_{2}$-nanotube array which was produced by anodic oxidation with their corresponding XRD patterns of AIP-deposited $\mathrm{Ti}$, as anodized $\mathrm{TiO}_{2}$ nanotubes array and post-annealed $\mathrm{TiO}_{2}$ nanotubes array.

\subsection{Summary}

Successful demonstration to prepare $\mathrm{TiO}_{2}$ nanotubes array by arc ion plating pre-deposit metal Ti layer on ITO glass followed by anodic oxidation has been carried out in this study to reveal the influence of anodization electrolyte variables and post-heat treatment on the microstructure of $\mathrm{TiO}_{2}$ nanotubes array and the photovoltaic behavior of the assembled DSSCs device. The key to successfully develop 10 micrometer long $\mathrm{TiO}_{2}$ nanotubes array lies in the strongly adhered Ti-layer which tolorates the electrolyte attack during anodic oxidation. Ultimate photovoltaic efficiency of $1.88 \%$ appears on the DSSC assembled from $\mathrm{TiO}_{2}$ nanotubes array which was annealed at $350{ }^{\circ} \mathrm{C}$. However, the annealing temperature that requires to form anatase phase through post-annealing would be detrimetal to the ITO front electrode and limits further increase in photovoltaic efficiency.

\section{Micro-arc oxidation and alkali etching to produce nanoflaky $\mathrm{TiO}_{2}$}

Micro-arc oxidation (MAO) technique is a relatively convenient and effective technique for producing micrometer scale porous crystalline anatase $\mathrm{TiO}_{2}$ over a metal titanium surface. This technique involves the anodically charging of a metal (similar to conventional anodic oxidation but with a higher level of discharge voltage) in a specific electrolyte to reach a critical value at which dielectric breakdown takes place, and initiates micro-arc discharge over the entire metal surface. The micro-arc discharge enables the rapid oxidation of the metal due to the effect of impact or tunneling ionization over the metal surface. The schematic MAO system to obtain $\mathrm{TiO}_{2}$ films is shown in Fig. 12. First attempt using MAO technique to grow microporous $\mathrm{TiO}_{2}$ over a Ti surface for applying as DSSC electrode has also demonstrated, with however limited photovoltaic efficiency due to unsatisfactory specific surface area. In responding to the demanding in high efficiency PV device, we have developed another two-step method for the $\mathrm{Ti}$ foil to grow nanoflaky $\mathrm{TiO}_{2}$. An idea is proposed in this study simply by using alkali etching to develop nanoflaky morphology 
over the pre-micro-arc oxidized $\mathrm{Ti}$ (i.e. $\mathrm{MAO}-\mathrm{TiO}_{2}$ ) as the ideal electron emitter (or $\mathrm{TiO}_{2}$ electrode). Such a nano featured $\mathrm{TiO}_{2}$ layer shall be able to exhibit very large specific surface area and capable of efficient dye absorbing and eventually high photovoltaic efficiency. The alkali etching began with the immersion the MAO treated titanium foil into a $\mathrm{NaOH}$ solution and soaking for $12 \mathrm{~h}$ to develop nano-featured $\mathrm{TiO}_{2}$. Later on, an alkali etching treatment followed by MAO was proposed to develop 3D-network nanostructural anatase $\mathrm{TiO}_{2}$ without annealing, with the accompanied photovoltaic efficiency substantially improved. In this work, a further detailed observation on the microstructural development of the nanostructural anatase $\mathrm{TiO}_{2}$ is carried out as a function of alkali bath concentration and post-heat treatment effect to the associated photovoltaic efficiency is correlated.

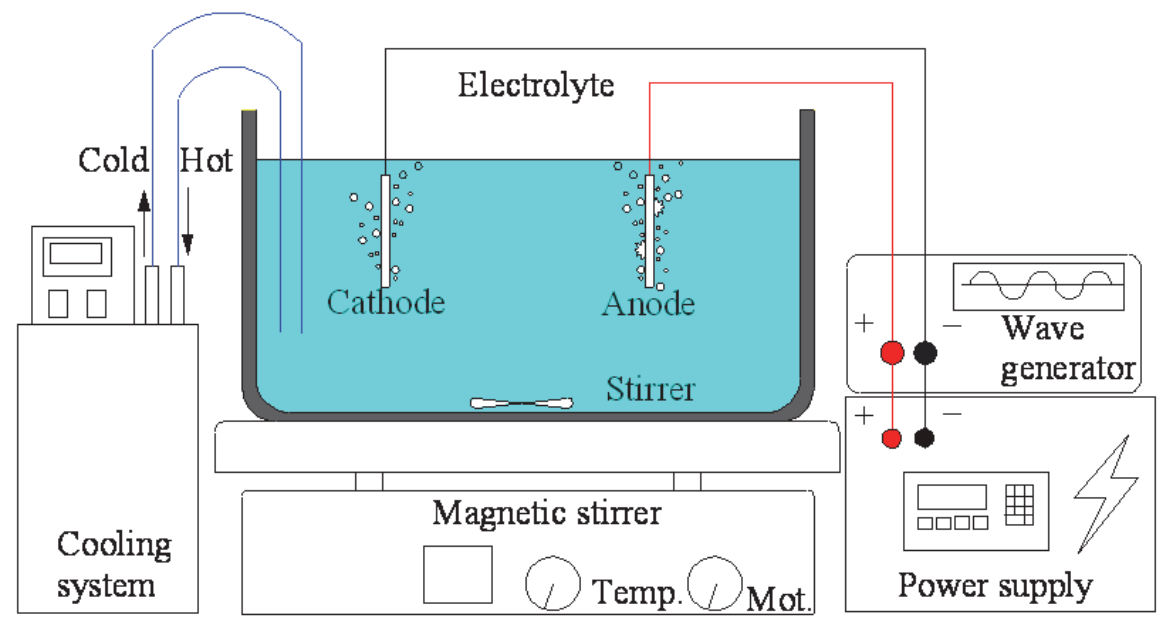

Fig. 12. Schematic diagram of micro-arc oxidation system to obtain $\mathrm{MAO}-\mathrm{TiO}_{2}$.

Figure. 13 shows the surface and cross sectional morphology of the MAO formed titania layer as well as the alkali etched $\mathrm{TiO}_{2}$ layers obtained at different bath concentration. After MAO treatment, the titanium forms porous crystallinic anatase $\mathrm{TiO}_{2}$ layer (as identified and described elsewhere) with numerous micrometer scale holes as observed in Fig. 13(a). These holes are discharge channels induced by the electrical breakdown of the oxide layer during the MAO treatment. It is worth noting that the surface is roughened, which is based on the fact that an intensive microdischarge occurs at a high voltage; as a result (Fig. 13(a)), the coating itself appears to be a microscopically splashed surface under the strong discharge effect. The morphology of the specimens alkali etched at different $\mathrm{NaOH}$ concentration shown in Fig. 13(b) (d) reveal that nanoflaky $\mathrm{TiO}_{2}$ can be developed through the alkali etching. The nano featured layer was developed over the $\mathrm{MAO}-\mathrm{TiO}_{2}$ scaffold surface with free interspace and nanoflakes of about $50 \sim 100 \mathrm{~nm}$ in size. As can be seen from the figure, these nanoflakes uniformly distribute over the entire surface of the treated specimen. The results revealed that alkali solution concentration appear to be an important variable in nanostructural control. Moreover, the higher $\mathrm{NaOH}$ concentration leads to much bigger free interspace and deeper nanoflaky $\mathrm{TiO}_{2}$ layer as well as bigger nanoflake size. It is therefore out of question that the $\mathrm{TiO}_{2}$ layer reformed by the alkali etching can have higher specific surface area than the $\mathrm{MAO}-\mathrm{TiO}_{2}$. Through the evaluation of a series of alkali-etched specimen at different $\mathrm{NaOH}$ concentrations, the size of the developed nanoflakes is found to 
be determined by the $\mathrm{NaOH}$ concentration. The morphological development of the nanoflakes is thought to be associated with the complicated dissolution and re-precipitation mechanism that involves the attack by hydroxyl groups and negatively charged $\mathrm{HTiO}_{3}$ ions formed on the surface. The $\mathrm{HTiO}_{3}{ }^{-}$ions are thought to be consequently attracted and dissolved by the positively charged ions in the $\mathrm{NaOH}$ solution. In our case, it is hypothetically proposed that the low-concentration $\mathrm{NaOH}$ solution gives rise to the diffusion control mode enabling charged ion exchange between the MAO specimen surface and the alkali solution, where a limited ion flux yields a low reaction rate that favors fine structure formation. Contrarily, the high $\mathrm{NaOH}$ bath concentration enables fast exchange of the charged ion species and fast structure formation (accompanied by the flakes grown in larger dimension and larger interspace). In addition, cracks occur to the nanoflaky $\mathrm{TiO}_{2}$ layer when $\mathrm{NaOH}$ bath concentration is increased. The results reflected in Fig. 13(c) and (d) indicate that the cracks began to form on the MAO specimen surface and grow with the increasing $\mathrm{NaOH}$ concentration.
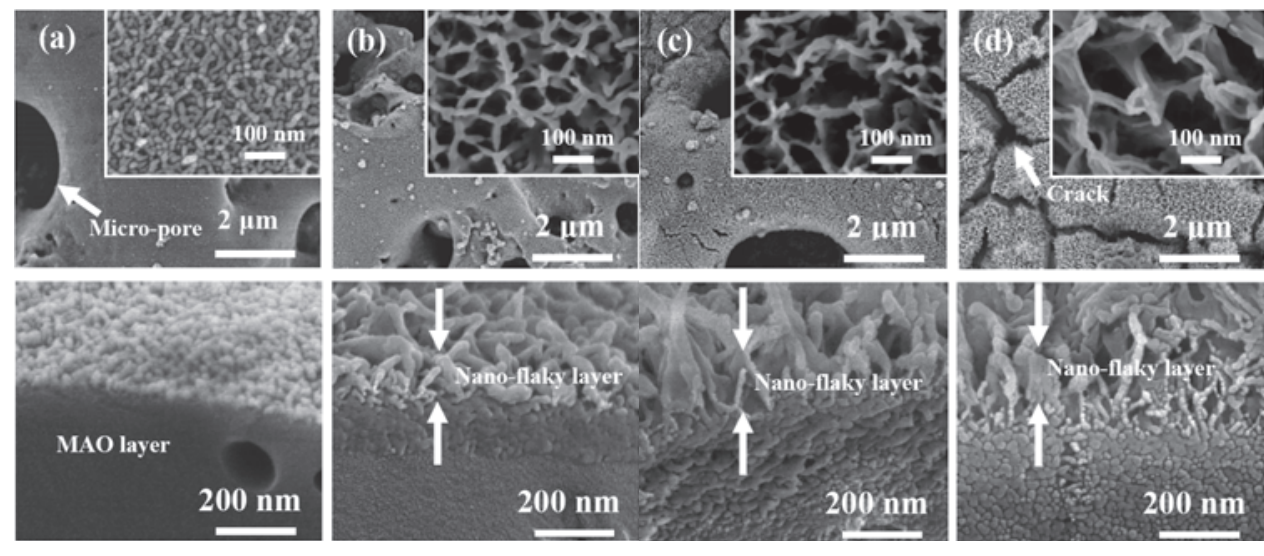

Fig. 13. Surface morphology (upper, with different magnification) and cross sectional morphology (lower) of the (a) MAO treated specimen, and alkali etched specimen in $\mathrm{NaOH}$ bath concentration of (b) $0.50 \mathrm{M}$ (c) $1.25 \mathrm{M}$ and (d) $2.50 \mathrm{M}$, respectively.

Further exam of the detailed microstructure of nanoflakes by using transmission electron microscope (TEM) in high magnification bright field images taken from specimen with alkali etching at $40^{\circ} \mathrm{C}$ for $12 \mathrm{~h}$ are shown in Fig. 14. It can be seen that the hair-like structure (corresponds to the nanoflaky structure as been observed in Fig. 13) exists over the $\mathrm{TiO}_{2}$ surface as shown in Fig. 14(a). Here, it clearly presents a 3D network fine structure. In addition, the hair-like structure grown from the inner wall of the pore as also observed in the Fig. 14(b) is again seen as a 3D network feature. These 3D nanoflakes led to a significant increase in specific surface area and presumably photovoltaic efficiency. It should also be noted that these pores and voids are opened to the alkali etched and their surfaces are also involved with the reforming process via dissolution and re-deposition. This means that the nanoflakes grow not only on the $\mathrm{TiO}_{2}$ surface but also grow deep into the inner surfaces, thereby significantly increase specific surface area, even though these nanoflakes unfortunately appear to be amorphous as identified by TEM selected area diffraction technique and described elsewhere. 

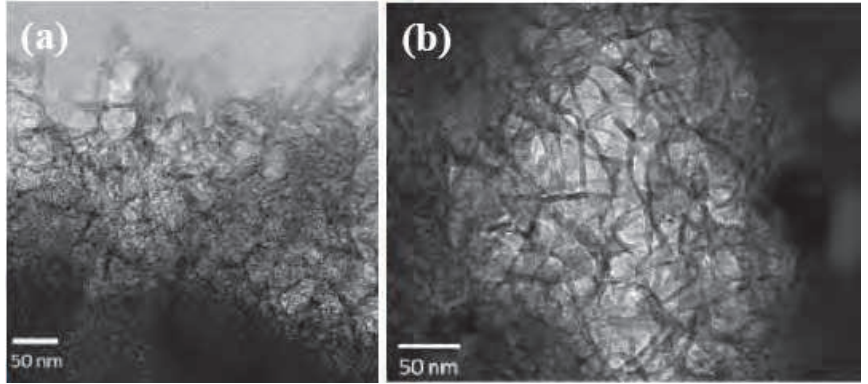

Fig. 14. Bright field image of nanoflaky $\mathrm{TiO}_{2}$ grown from (a) the $\mathrm{MAO}-\mathrm{TiO}_{2}$ surface and (b) the inner pore of the $\mathrm{MAO}-\mathrm{TiO}_{2}$.

The $I-V$ curves of DSSCs assembled with the $\mathrm{MAO}-\mathrm{TiO}_{2}$ and alkali etched $\mathrm{TiO}_{2}$ obtained at different concentrations are shown in Fig. 15.

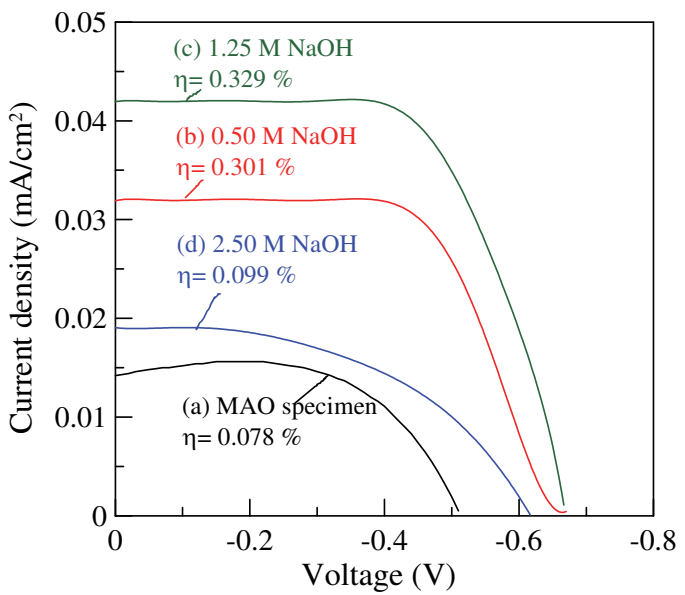

Fig. 15. I- $V$ characteristic of the DSSC device assembled using (a) MAO treated specimen and alkali etched specimens at different $\mathrm{NaOH}$ bath concentration.

Photovoltaic efficiency of the assembled DSSC is substantially increased by alkali etching. Apparently, the remarkable increase in the $J_{s c}$ and $V_{o c}$ of the cell assembled from alkali etched specimens appear to be contributed to by the nanoflaky surface structure, which possesses a markedly higher specific surface area than the MAO layer. Note that the $J_{s c}$ is significantly dropped for the DSSC using alkali etched $\mathrm{TiO}_{2}$ specimen prepared at $2.5 \mathrm{M}$ $\mathrm{NaOH}$. This is due to the cracks formed and distributed over the entire oxide layer leaving the $\mathrm{I}_{2}+\mathrm{LiI}$ electrolyte to directly contact with fresh metallic titanium plate. A close look at Fig. 13(b), (c) and (d), the DSSC assembled by the alkali etched specimen at $1.25 \mathrm{M} \mathrm{NaOH}$ solution performs the highest $J_{s c}$ and $V_{o c}$ among the three alkali etched specimens. Good explanation is that this is a compromising of the effect of the enlarged specific surface area and the effect of crack formation caused by the alkali etching, i.e. the increased $\mathrm{NaOH}$ bath concentration not only results in the increased specific surface area but also the increased free interspace and even worse the crack formation. As revealed in Fig. 13(d), the cracks 
causing the discontinuity of path for charge carrier shall be the main reason for the significant decrease in photovoltaic efficiency of the assembled DSSC which employs specimen alkali etched at $0.50 \mathrm{M} \mathrm{NaOH}$. By comparison, the DSSC assembled by using MAO scaffold presents a photovoltaic efficiency of $0.078 \%$, while it present a highest photovoltaic efficiency of $0.329 \%$ (over four times increment) for the DSSC assembled by the alkali etched specimen. Through this simple and low cost alkali etching route, it is able to produce nano structural $\mathrm{TiO}_{2}$ electrode for photovoltaic DSSC.

The $I-V$ characteristics of the DSSCs assembled by using specimens with $\mathrm{MAO}-\mathrm{TiO}_{2}$ and nanoflaky $\mathrm{TiO}_{2}$ (as-etched and annealed at $400{ }^{\circ} \mathrm{C}$ ), with their corresponding XRD patterns are shown in Fig. 16. The annealing work significantly improves the crystallinity of the nanoflakes and consequently photovoltaic efficiency can be dramatically increased for the device assembled with the specimen with nanoflaky $\mathrm{TiO}_{2}$. It was $0.329 \%$ for the specimen with the as-etched nanoflaky $\mathrm{TiO}_{2}$ and $2.194 \%$ for the specimen with annealed nanoflaky $\mathrm{TiO}_{2}$. Both are however greater than that of the $\mathrm{MAO}-\mathrm{TiO}_{2}$ specimen only with $0.061 \%$. By contrast, the $J_{s c}$ and $V_{o c}$ of the solar cell assembled by alkali etched specimen are substantially higher. Apparently, the dramatic increase in $J_{s c}$ and $V_{o c}$ of the cell assembled by alkali treated specimens is contributed by the nanoflaky surface structure, which possesses far higher specific surface area than MAO layer does. With this simple and low cost postalkali etching demonstration, the photovoltaic efficiency of the DSSC using the MAO treated $\mathrm{Ti}$ foil as the back electrode can be significantly increased. The increased crystallinity provides higher dye-absorption for generating more electron-hole pairs and suppresses the electron loss due to the recombination of electron-hole pairs. Therefore, the DSSC assembled with $\mathrm{Ti}$ electrode which synthesized by $\mathrm{MAO}$, treated by alkali etching and annealing, presents highest photovoltaic efficiency.
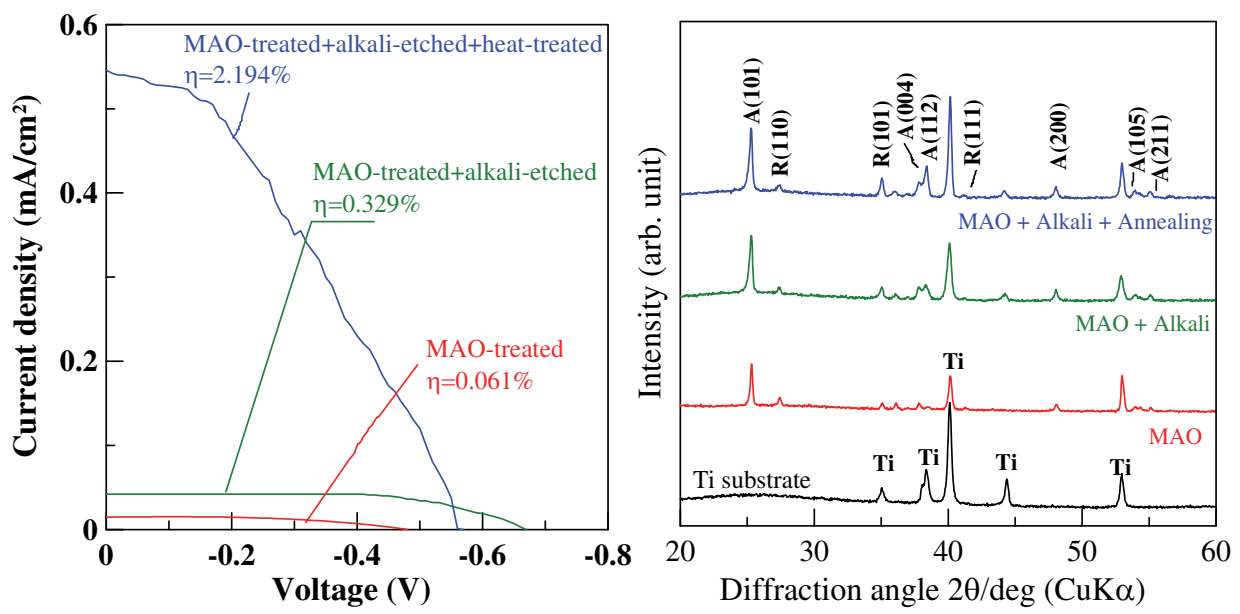

Fig. 16. The $I-V$ characteristics of the DSSCs assembled by using specimens with $\mathrm{MAO}-\mathrm{TiO}_{2}$ and nanoflaky $\mathrm{TiO}_{2}$ (as-etched and annealed at $400{ }^{\circ} \mathrm{C}$ ), with their corresponding XRD patterns. 


\subsection{Summary}

Here at last, a method to combine with micro-arc oxidation and post-alkali etching has succeeded in forming an 3D network nanoflaky anatase $\mathrm{TiO}_{2}$ layer on the surface of a $\mathrm{Ti}$ substrate. The nanoflaky $\mathrm{TiO}_{2}$ completely cover the upmost surface of the $\mathrm{MAO} \mathrm{TiO}_{2}$ layer as well as the inner pores and voids, therefore provides very large surface area for dye absorption to increase the efficiency of the assembled DSSCs. Without post-annealing, maximum photovoltaic efficiency of $0.329 \%$ for the DSSC is achieved with the amorphous nanoflaky $\mathrm{TiO}_{2}$ layer alkali etched at $1.25 \mathrm{M} \mathrm{NaOH}$. Post-annealing at $400{ }^{\circ} \mathrm{C}$ significantly enhances crystallinity of the nanoflaky $\mathrm{TiO}_{2}$ layer and ultimately photovoltaic efficiency $2.194 \%$ for the DSSC is achieved. The above results have shown that the method to combine with micro-arc oxidation and post-alkali etching was a potential and low-cost process for developing the nano featured $\mathrm{TiO}_{2}$ photoanode for obtaining high efficiency DSSC. However, post-annealing shall not be abandoned for additional windfall of the photovoltaic efficiency.

\section{Conclusion}

Here, we begin our conclusion by reviewing the results in previously described. We started developing nano featured $\mathrm{TiO}_{2}$ layer by using LPD method and found that it is capable of obtaining nanocluster $\mathrm{TiO}_{2}$ with unacceptable growth rate. Crystallinic anatase $\mathrm{TiO}_{2}$ layer can be obtained through suitable annealing treatment to achieve only $0.0056 \%$ photovoltaic efficiency. In the work of $\mathrm{TiO}_{2}$ nanowires growth on $\mathrm{AIP}-\mathrm{TiO}_{2}$ template via hydrothermal route, an ultimate PV efficiency of $3.63 \%$ can be achieved by optimizing hydrothermal process condition and annealing treatment. A hydrothermal treatment time so long as 24 hours shall be required for achieving this, which however has shorter treatment time than the LPD process and a fair PV efficiency. In the work of preparing $\mathrm{TiO}_{2}$ nanotubes array by arc ion plating pre-deposit metal Ti layer on ITO glass followed by anodic oxidation, the key to successfully develop 10 micrometer long $\mathrm{TiO}_{2}$ nanotubes array lies in the strongly adhered Ti-layer which tolorates the electrolyte attack during anodic oxidation. Ultimate photovoltaic efficiency of $1.88 \%$ appears on the DSSC assembled from $\mathrm{TiO}_{2}$ nanotubes array which was annealed at $350{ }^{\circ} \mathrm{C}$. Although the tube length and diameter is controllable, it is expected to exhibit higher photovoltaic efficiency by further reducing tube diameter for more specific surface area of the photoanode. At last, a DSSC assembled from the nanoflaky $\mathrm{TiO}_{2}$ prepared by using micro-arc oxidation and alkali etching was demonstrated. Ultimate photovoltaic efficiency $2.194 \%$ for the DSSC is achieved.

Results in these studies are remarkably consistent with what we expected. Cost saving and easy operation processes for obtaining $\mathrm{TiO}_{2}$ photoanode has been achieved. Despite the encouraging result of this study as the positive effect of nanostructural surface engineering, future research is required in a number of directions about chasing high efficiency DSSCs. However, a step further has been taken in the improved photovoltaic efficiency by nanostructural surface engineering and an opportunity for commercializing DSSC using low-cost process.

\section{References}

O’Regan, B. \& Grätzel, M. (1991). Letters to nature, Vol.353, pp. 733-740

Nagayama, H., Honda, H. \& Kawahara., H. (1988). Journal of the Electrochemical Society, Vol.135, pp. 2013-2014 
Herbig, B. \& Löbmann, P. (2004). Journal of Photochemistry and Photobiology A: Chemistry, Vol.163, pp. 359-365

He, J. L., Chen, C. H. \& Hsu, M. Y. (2006). The Chinese Journal of Process Engineering, Vol.6, pp. 224-227

Rao, C. N. R., Satishkumar, B. C., Govindaraj, A., Vogl, E. M. \& Basumallick, L. (1997). Journal of Materials Research, Vol.12, pp. 604-606

Kasuga, T., Hiramatsu, M., Hoson, A., Sekino, T. \& Niihara, K. (1999). Advanced Materials, Vol.11, pp. 15-18

He, J. L., Hsu, M. Y., Li, H. F. \& Chen, C. H. (2006). The Chinese Journal of Process Engineering, Vol.2, pp. 228-234

Shankar, K., Mor, G. K., Prakasam, H. E., Yoriya, S., Paulose, M., Varghese, O. K. \& Grimes, C. A. (2007). Nanotechnology, Vol.18, pp.065707

Chen, C. H., Chen, K. C. \& He, J. L. (2010). Current Applied Physics, Vol.10, pp. S176

Yerokhin, A. L., Nie, X., Leyland, A., Matthews, A. \& Dowey, S.J. (1999). Surface and Coatings Technology, Vol.122, pp. 73-93

Song, W., Xiaohong, W., Wei, Q. \& Zhaohua, J. (2007). Electrochimica Acta, Vol.53, pp.18831889

Wei, D., Zhou, Y., Jia, D. \& Wang, Y. (2008). Acta Biomaterialia, Vol.254, pp.1775-1782

Wu, S. Y., Lo, W. C., Chen, K. C. \& He, J. L. (2010). Current Applied Physics, Vol.10, pp.S180S183.

Wu, S. Y., Chen, Y. H., Chen, K. C. \& He, J. L. (2010). Japanese Journal of Applied Physics, Vol.10, pp.180-183.

Chu, P. J, Wu, S. Y., Yerokhin, A., Matthews, A. \& He, J. L. (2009). Program and Abstract Book of TACT 2009 International Thin Films Conference, (December 2009.) pp.115-116 


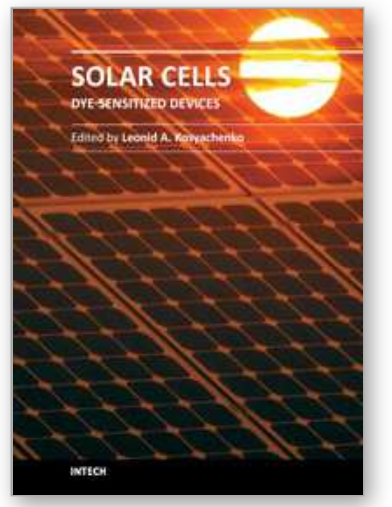

\author{
Solar Cells - Dye-Sensitized Devices \\ Edited by Prof. Leonid A. Kosyachenko
}

ISBN 978-953-307-735-2

Hard cover, 492 pages

Publisher InTech

Published online 09, November, 2011

Published in print edition November, 2011

The second book of the four-volume edition of "Solar cells" is devoted to dye-sensitized solar cells (DSSCs), which are considered to be extremely promising because they are made of low-cost materials with simple inexpensive manufacturing procedures and can be engineered into flexible sheets. DSSCs are emerged as a truly new class of energy conversion devices, which are representatives of the third generation solar technology. Mechanism of conversion of solar energy into electricity in these devices is quite peculiar. The achieved energy conversion efficiency in DSSCs is low, however, it has improved quickly in the last years. It is believed that DSSCs are still at the start of their development stage and will take a worthy place in the largescale production for the future.

\title{
How to reference
}

In order to correctly reference this scholarly work, feel free to copy and paste the following:

Ying-Hung Chen, Chen-Hon Chen, Shu-Yuan Wu, Chiung-Hsun Chen, Ming-Yi Hsu, Keh-Chang Chen and JuLiang $\mathrm{He}$ (2011). Chasing High Efficiency DSSC by Nano-Structural Surface Engineering at Low Processing Temperature for Titanium Dioxide Electrodes, Solar Cells - Dye-Sensitized Devices, Prof. Leonid A. Kosyachenko (Ed.), ISBN: 978-953-307-735-2, InTech, Available from: http://www.intechopen.com/books/solar-cells-dye-sensitized-devices/chasing-high-efficiency-dssc-by-nanostructural-surface-engineering-at-low-processing-temperature-fo

\section{INTECH}

open science | open minds

\section{InTech Europe}

University Campus STeP Ri

Slavka Krautzeka 83/A

51000 Rijeka, Croatia

Phone: +385 (51) 770447

Fax: +385 (51) 686166

www.intechopen.com

\section{InTech China}

Unit 405, Office Block, Hotel Equatorial Shanghai

No.65, Yan An Road (West), Shanghai, 200040, China

中国上海市延安西路65号上海国际贵都大饭店办公楼 405 单元

Phone: +86-21-62489820

Fax: $+86-21-62489821$ 
(C) 2011 The Author(s). Licensee IntechOpen. This is an open access article distributed under the terms of the Creative Commons Attribution 3.0 License, which permits unrestricted use, distribution, and reproduction in any medium, provided the original work is properly cited. 